\title{
INVESTIGATION OF PROCESS COLOURS VARIATIONS OF ELECTROPHOTOGRAPHY COLOUR PRODUCTION PRESSES
}

\author{
Iskren Spiridonov (D), Simeon Yordanov (D), Rumyana Boeva (D), Aleksandar Milkov \\ University of Chemical Technology and Metallurgy, \\ Department of Pulp, Paper and Printing Arts, Sofia, Bulgaria
}

\begin{abstract}
In this investigation is approached method for assessing and evaluation of colour repeatability and variation for digital electrophotography printing presses. Two of most popular midlevel electrophotography colour production presses were chosen. These presses are widely used in printing houses for the printing of book covers, posters, etc. in small circulations. The similar perception of quality of digital production to the offset printing quality (ISO 12647-2:2013) is required from most of the clients of printing houses, publishers, etc. One of the problems of midlevel electrophotography colour production presses are variations of colours in the printing run and variations of colours during the time - weeks, months, years. The variation degree depends on many factors like - the precision of internal calibration method and types of sensors during the printing run, quality of used materials, calibration precision made by press operator, temperature and humidity variation, etc. (Kachin, Spiridonov, 2000) Specially designed for experiment test forms have been printed on two of most widely used materials for book covers, business cards, etc. $-300 \mathrm{~g} / \mathrm{m} 2$ matt-coated board and $300 \mathrm{~g} / \mathrm{m} 2$ offset uncoated board. The evaluation method is based on colorimetrical and densitometrical measurements (Kachin, Spiridonov, 2004) of 100 continuous printed sheets. The experiment was repeated in different time periods -between 6 hours and 4 months, to collect data for colour variation between reprinting the same test images in the time.
\end{abstract}

Key words: Digital printing, printing quality, colour variation, electrophotography, colour reproduction accuracy

\section{INTRODUCTION}

Digital printing systems are designed to cover the production of small circulations and are aimed at reproducing the printing quality of offset printing Printing Presses, combined with shorter runtime and save the expenses on creating print forms for every colour. Digital electrographic printing systems are used to create marketing materials, brochures, books, photobooks, calendars, tickets, magazines, foldable boxes, flexible packages, labels, posters, etc. (Kipphan, 2001).

Digital printing technology allows for the creation of full colour prints which can be customizable or customized even during production. Digital Presses are no longer required to stop in order to load new printing forms for each and every new incoming order.

The digital electrophotographic printing method is one of the most widely spread and fast developing techniques in the past few years. It is perfectly suited to print individual items, covers, business cards, labels and magazines in small circulations, as well as to put additional circulations to the result of offset printing, etc. Whenever there is need to supplement the core circulation, the customer, naturally, wishes to attain the same colours he had during offset printing. To meet this goal, it is necessary to use quality print media as recommended by the manufacturer of the corresponding electrophotographic printing press. The manufacturers of digital print media, on the other hand, use their own brands with different properties and features (whiteness, texture, type of coatings, smoothness, wear resistance, mechanical properties, etc.). The majority of print houses, however, use lower end alternatives to manufacturer's recommendation. The quality of these substitute printing media is considerably lower and this often leads to un uniformity of contents and un uniformity of thickness, which in turn inevitably lead to bad colour reproduction, colour variations within the circulation, inconsistencies, etc.

One of the problems when using this type of printing technology is the presence of colour variation within the circulation. Another important factor is the presence of colour difference between two separate circulations. This variation is largely due to climate changes within the printing hall, which may include humidity, temperature, change of seasons, paper acclimatisation, paper transport and storage conditions, paper quality, etc.

It is also paramount to consider the type of print media (paper or board) itself as designated for digital print purposes. 


\section{EXPERIMENTAL}

For the purposes of the current test, the team has modelled designated samples in the A3 format, which include specific ranges and control elements, all considered according to the specifics of electrophotographic print (International Organization for Standardization, ISO 12647-7:2016, 2016). Some of the pictures for visual analysis materials are taken from FOGRA, ECI, etc. due to the fact they are widely used while testing conventional and digital printing presses, and because every professional would catch the slightest deviation in tone and colour reproduction (Kraushaar, 2018). Test forms contain varied elements to analyse the colour characteristics of the four fundamentals (CMYK), backgrounds made of varied number of colours, gradation ranges $0-100 \%$ with varied steps $1-10 \%$ for CMYK, etc.

Besides optical density, there is investigation on colour variations within the circulation. It is noted, that in some cases, due to printing environment conditions change (such as air humidity, temperature in the printing hall, paper tempering) there is variations in colours and optical density.

Some of the ranges of test forms used are shown in Figure 1.
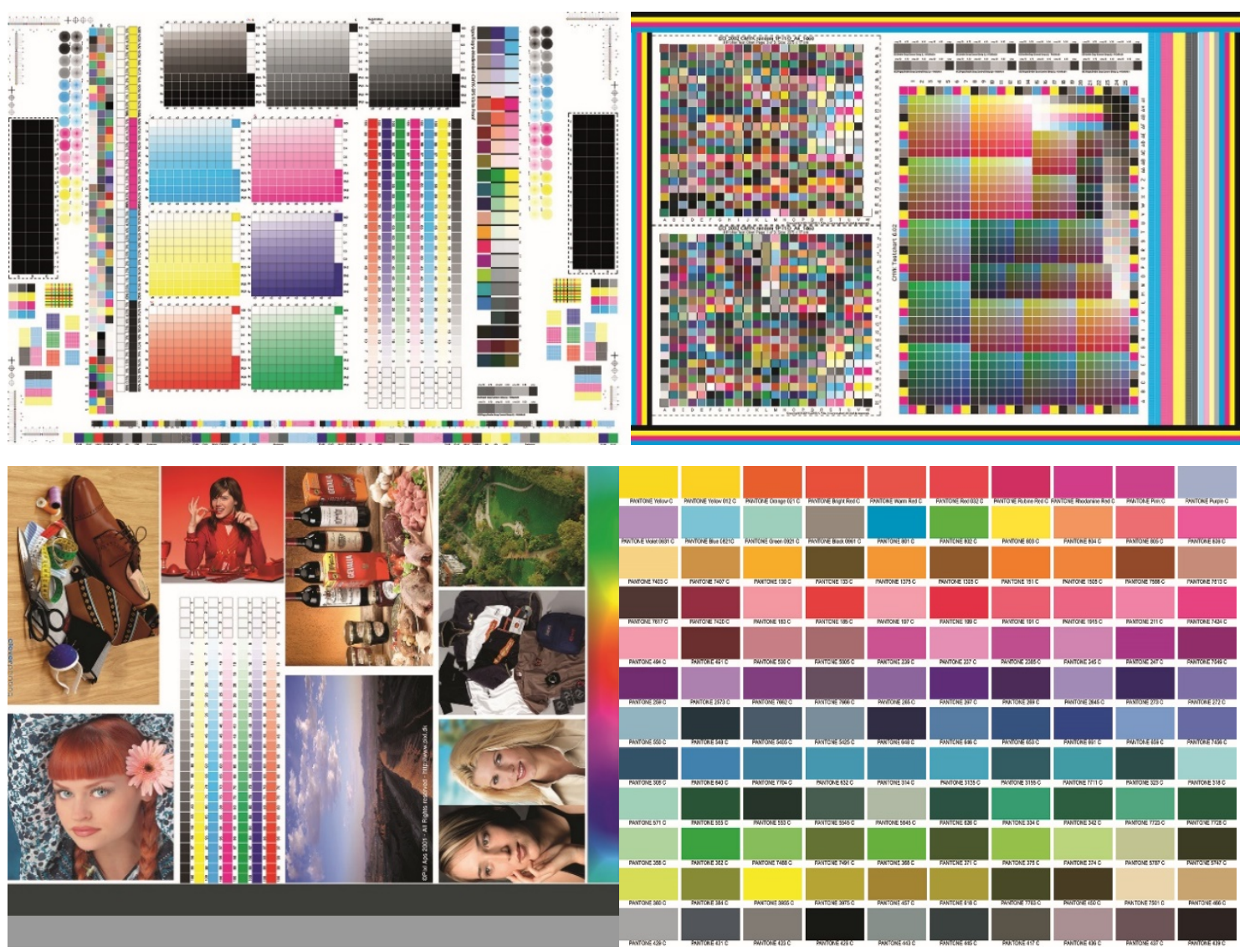

Figure 1: Some test forms, used during the investigation phase

Testing forms are printed with presents for different ICC colour profile outputs, depending of used paper board type (ICC - International Color Consortium, 2020). Before printing the test runs, all 2 digital presses underwent calibration according manufacturer's instruction with the aid of spectrophotometer.

\subsection{Test materials used}

The test incorporates two types of cardboards. They were chosen due to their mass use in print houses thanks to their optimal price, and also because they present an affordable solution with good optical features, but with lower printability in terms of digital printing.

1. Surface matt coated board (colour characteristics $L=96.33 a=1.19 \mathrm{~b}=-5.84), 300 \mathrm{~g} / \mathrm{m}^{2}$

2. Plain offset uncoated board ( $L=95.56 \mathrm{a}=2.71 \mathrm{~b}=-10.69), 300 \mathrm{~g} / \mathrm{m}^{2}$ 
Before every test, regardless if it is on a conventional or digital printing press, one can vary within the parameter tolerances, considering the required precision and the test goals. In this case study, the fundamental goal is to investigation the factors, forming image quality, their consistency and the possibilities to achieve quality printing over mass-used affordable materials.

\subsection{The test completion comprehends the following parameters:}

1. Optical density variation of $100 \%$ CMYK fields (CMYK solid tones) for circulation of 100 pcs.

2. Colour variation of $100 \%$ CMYK fields (CMYK solid tones), expressed in colour difference $-\Delta \mathrm{E}_{76}$ and $\Delta \mathrm{E}_{2000}$ for circulation of 100 pcs.

3. Optical density variation of $100 \%$ CMYK fields (CMYK solid tones) as function of time - between 6 hours and 4 months.

4. Colour variation of $100 \%$ CMYK fields (CMYK solid tones), expressed in colour differences $-\Delta \mathrm{E}_{76}$ and $\Delta \mathrm{E}_{2000}$ as function of time - between 6 hours and 4 months.

The authors would like to abstract the precise brands and models of the digital electrographic print presses in order to prevent influencing customer's choice, and also to propose an investigation methodology combined with what has to be considered when purchasing that type of Printing Press. This is why one may observe that the Printing Presses have been denoted as Electrophotography printing press 1 (EPP 1) and Electrophotography printing press 2 (EPP2). EPP 1 and EPP 2 are among the most common electrophotographic digital printing systems.

The experiment at hand focuses on exploring a multitude of adjacent factors, all relative to colour reproduction quality, which have not been included in the scope of this paper due to their volume. The latter will be presented in sequel publications.

\section{RESULTS AND DISCUSSION}

Colour variation within the circulation and between orders as a function of time is one of the fundamental problems facing all printing houses. It is due to a number of factors that colour tone variation impacts digital electrophotographic presses from the mid-price tier and less in the high-price tier.

In order to investigation colour tone variation within the circulation, a run of 100 consecutive sheets were made for both the matt and offset boards. Optical density and colour characteristics have been measured in identical spots for $100 \%$ CMYK fields throughout the print run.

\subsection{Investigation on the optical density variation of $100 \%$ CMYK fields (CMYK solid tones) for circulation of 100 pcs.}

The measurements of colour coordinates are made using a spectrophotometer under the following conditions (MediaStandard Print, 2018):

- $\quad$ Standard illuminant D50;

- $\quad 2^{\circ}$ standard observer;

- No polarisation filter;

- $\quad$ Measurement geometry $-45^{\circ} / 0^{\circ}$ or $0^{\circ} / 45^{\circ}$;

- Measuring aperture $-4 \mathrm{~mm}$;

Figure 2 shows optical density variations of 100\% CMYK fields, matt coated board, EPP1 and EPP2 printing press.

For matt board, results show optical density variation in the circulation (compared to the first sheet) as follows Cyan \pm 0.04 , Magenta \pm 0.05 , Yellow \pm 0.03 and Black \pm 0.02 for EPP 1 and Cyan \pm 0.11 , Magenta \pm 0.14 , Yellow \pm 0.05 and Black \pm 0.05 for EPP2

Figure 3 shows optical density variations of 100\% CMYK fields, offset uncoated board,EPP1 and EPP2 printing press.

For matt board, results show optical density variation in the circulation (compared to the first sheet) as follows Cyan \pm 0.03 , Magenta \pm 0.02 , Yellow \pm 0.03 and for Black \pm 0.04 for EPP 1 and Cyan \pm 0.06 , Magenta \pm 0.07 , Yellow \pm 0.13 and for Black \pm 0.06 for EPP2. 


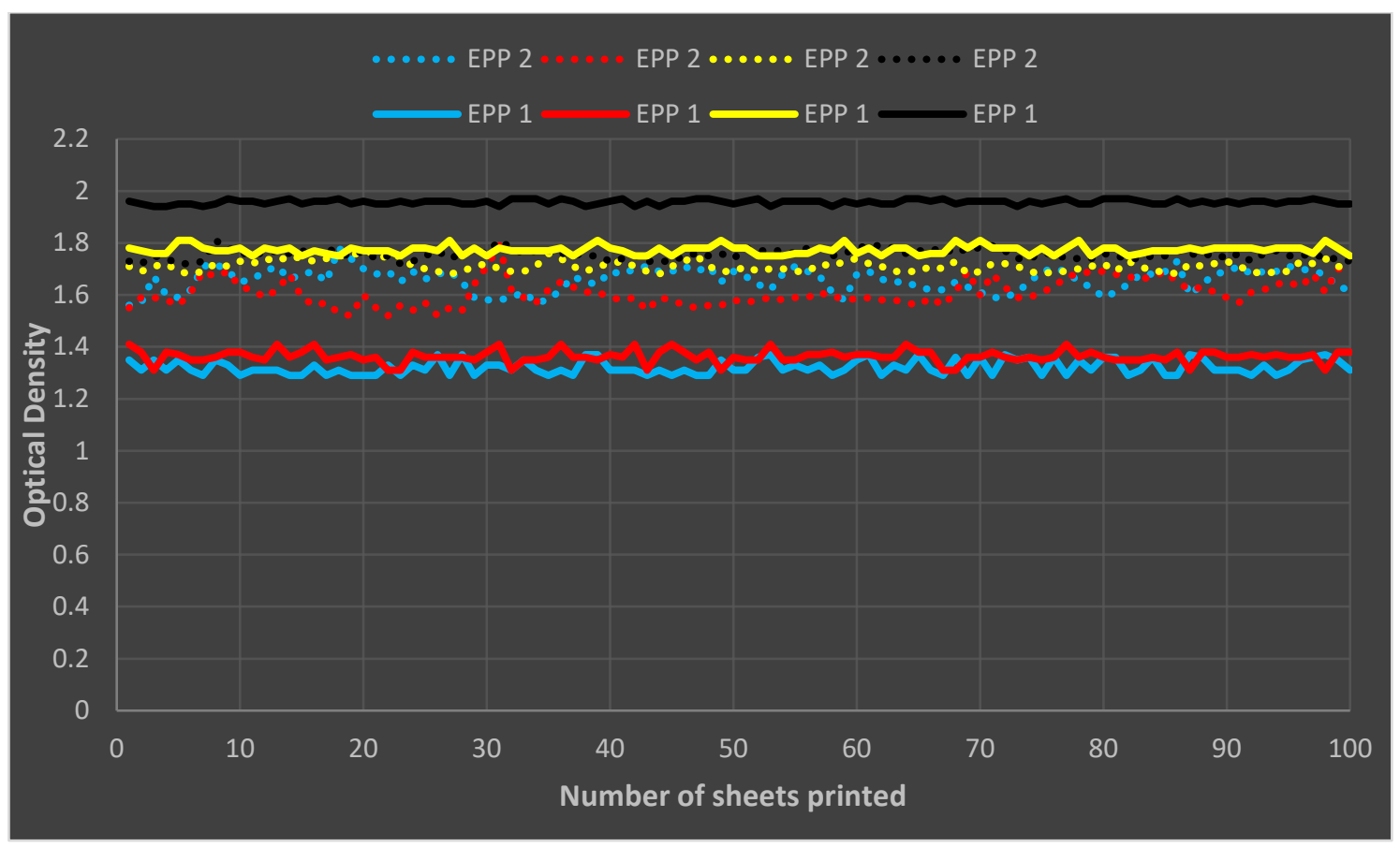

Figure 2: Graphic representation of optical density variation within a print run of 100 consecutive sheets of matt coated board

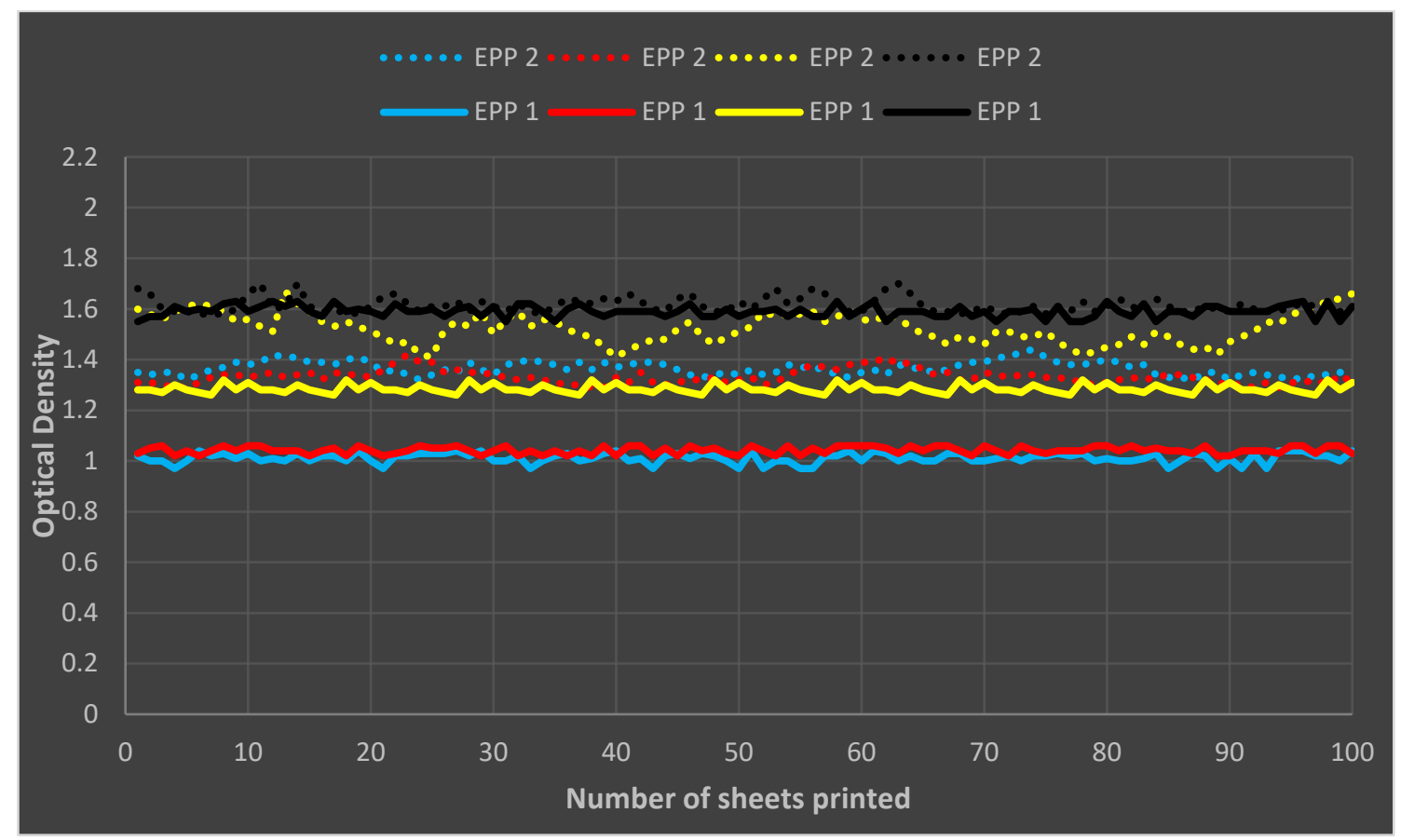

Figure 3: Graphic representation of optical density variation within a print run of 100 consecutive sheets of offset uncoated board 


\subsection{Investigation of the colour characteristics variation of $100 \%$ CMYK fields, expressed with colour difference $-\Delta \mathrm{E}_{76} \mathrm{n} \Delta \mathrm{E}_{2000}$ over a print run of 100 pcs.}

Due to electrographic digital print, and in order to get an even more precise characterisation of colour variation within the circulation, an additional investigation concerning colour variations over CMYK fields was made for the print run of 100 pcs. This variation is presented in the calculation of colour difference $\Delta E_{76}$ and $\Delta E_{2000}$ over the entire print run compared to the first sheet. The notation and representation of colour tone variation via deltas is made in order to allow maximal consideration of the particularities relative to human eye perception. Apart from the latter, this is the way to determine and limit colour variation in ISO printing standards as applied worldwide by the graphic technology.

Figure $4(a, b, c, d)$ shows the CMYK colour difference variation (compared to the first sheet) within the circulation of matt board from both EPP 1 и EPP 2 (Electrophotography Printing Press-EPP), where these are some of the most common electrophotographic printing systems available on the market.

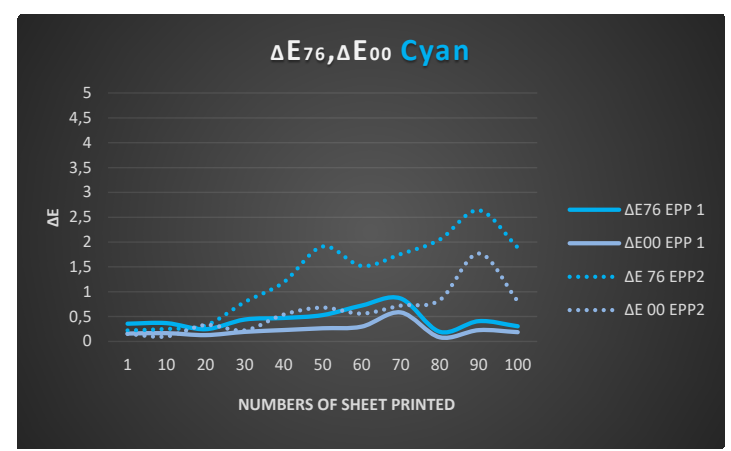

a.

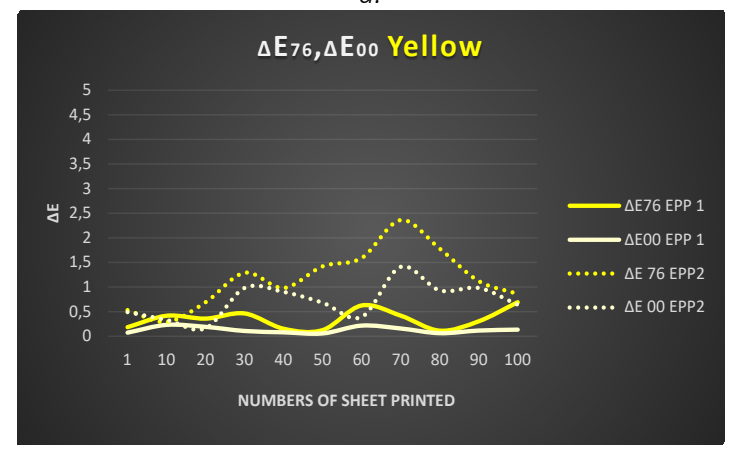

C.

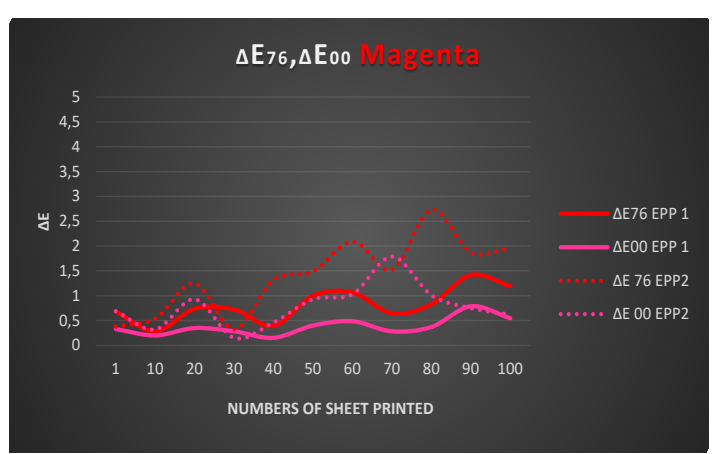

b.

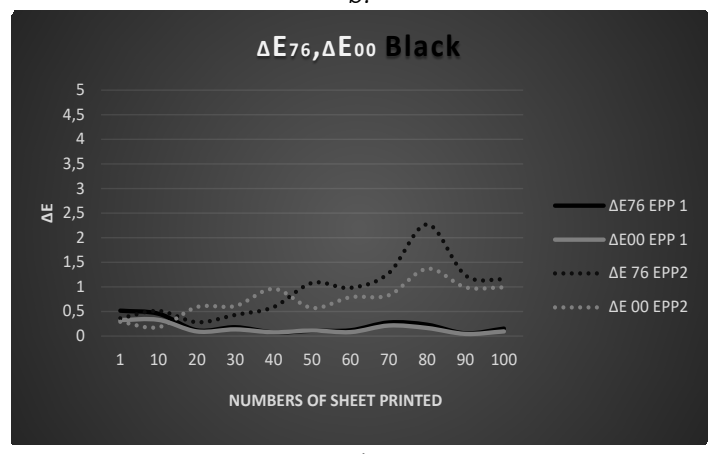

d.

Figure 4: Colour variation of $C M Y K$ expressed by $\triangle E_{76}$ and $\triangle E_{2000}$ during a print run of matt coated board in both EPP 1 and EPP 2 (Electrophotography Printing Press-EPP).

Matt board in EPP1 yielded out average colour variation for the print run (compared to the first sheet) as follows: Cyan $\Delta \mathrm{E}_{2000}=0.27$, Magenta $\Delta \mathrm{E}_{2000}=0.38$, Yellow $\Delta \mathrm{E}_{2000}=0.14$ and Black $\Delta \mathrm{E}_{2000}=0.37$. Maximal values of $\Delta E_{2000}$ vary between 0.27 and 0.78 . Matt board in EPP 2 yielded out average colour variation for the print run (compared to the first sheet) as follows: Cyan $\Delta \mathrm{E}_{2000}=0.65$, Magenta $\Delta \mathrm{E}_{2000}=0.83$, Yellow $\Delta \mathrm{E}_{2000}=0.76$ and Black $\Delta E_{2000}=0.82$. Maximal values of $\Delta E_{2000}$ vary between 1.37 and 1.79 .

Figure 5 ( $a, b, c, d)$ shows the CMYK colour variations (compared to the first sheet) within the circulation of offset board from both EPP 1 and EPP 2.

Offset board yielded out average colour variation for the print run (compared to the first sheet) as follows: Cyan $\Delta \mathrm{E}_{2000}=0.31$, Magenta $\Delta \mathrm{E}_{2000}=0.41$, Yellow $\Delta \mathrm{E}_{2000}=0.15$ and Black $\Delta \mathrm{E}_{2000}=0.75$. Maximal values of $\Delta \mathrm{E}_{2000}$ vary between 0.32 and 1.35. Offset board in EPP2 yielded out average colour variation for the print run (compared to the first sheet) as follows: Cyan $\Delta \mathrm{E}_{2000}=0.70$, Magenta $\Delta \mathrm{E}_{2000}=0.88$, Yellow $\Delta \mathrm{E}_{2000}=1.78$ and Black $\Delta \mathrm{E}_{2000}=1.01$. Maximal values of $\Delta \mathrm{E}_{2000}$ vary between 1.56 and 2.93.

Both paper types, when printed via EPP 1 show very little colour variation $\Delta E_{2000}$ values, the maximum of which is $\Delta \mathrm{E}_{2000}=0.78$ for $C M Y K$ - a negligible value. EPP 2 and the exact same two board types, yielded colour variation $\Delta E_{2000}$ values, the maximum of which reaches 2.93 , which is within standard tolerances and is completely satisfactory as a result. 


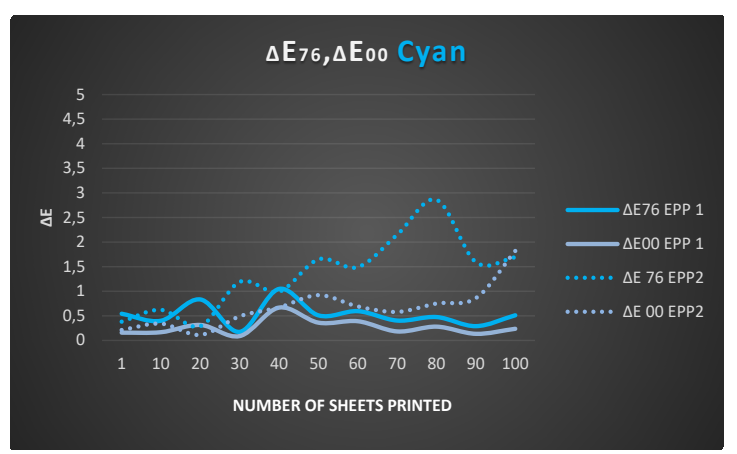

a.

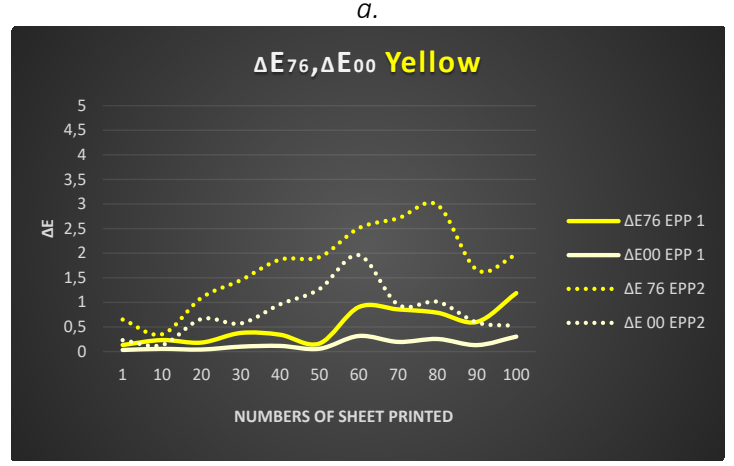

C.

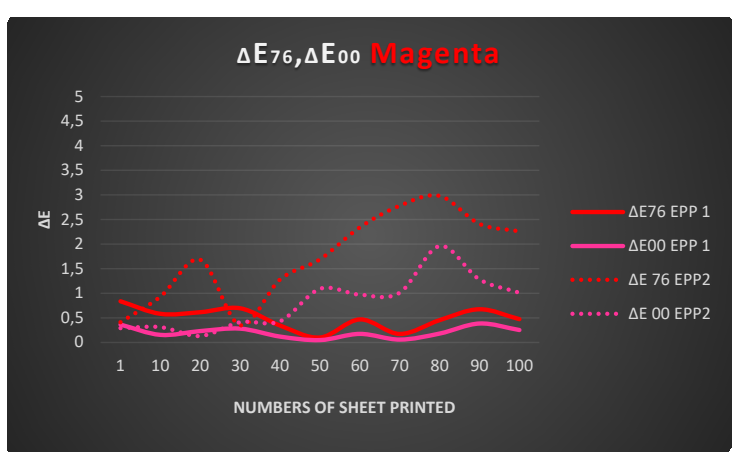

b.

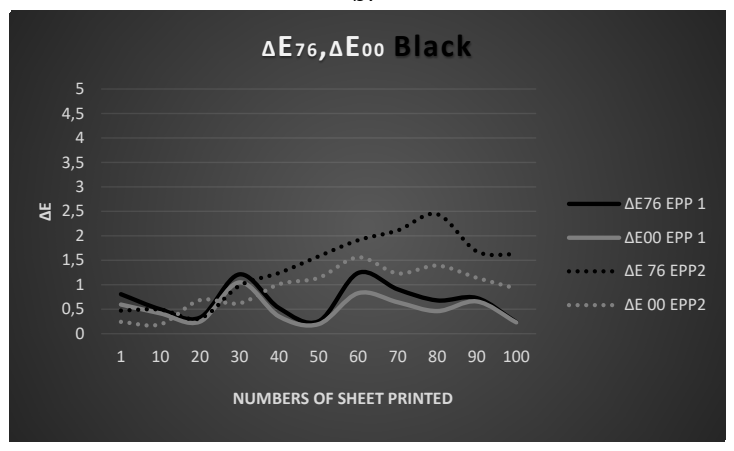

d.

Figure 5: Colour variation of CMYK expressed by $\triangle E_{76}$ and $\triangle E_{2000}$ during a print run of offset uncoated board in both EPP 1 and EPP 2 (Electrophotography Printing Press-EPP).

\subsection{Investigation of $\Delta E_{76}$ and $\Delta E_{2000}$ colour variation of $100 \%$ CMYK fields (CMYK solid tones) as a function of time - between 6 hours and 4 months.}

One of the problems with digital electrographic print presses is colour variation, which is visible when printing the same order after a certain amount of time. Practically anyone has come across evident colour variations while re-printing covers, business cards, etc. Often times these differences are due to irregular calibration or the lack of an algorithm to do that in lower-priced printing presses.

In order to investigation this factor, two parameters have been observed as defining colour difference in re-print - difference within one business day and difference within a long period of time -4 months. This investigation excludes the black colour due to the fact it has high optical density values and very low brightness $L=8-9$, which makes it impossible for the human eye to catch any of its nuances, therefore rendering it irrelevant in this case. The average colour difference are calculated for 100 sheet print run on each colour C, M, Y, K and based on the results the colour difference over short and long period of time are calculated.

Table 1: Colour variations $\triangle E_{2000}$ for $C M Y$ between two orders over short period of time for matt coated and offset uncoated board, printed on EPP1 and EPP2

\begin{tabular}{|l|c|c|c|c|}
\hline & $\begin{array}{c}\text { Colour difference } \\
\Delta \mathrm{E}_{2000} \text { for 2 orders }- \\
\text { short interval- }(6 \mathrm{hrs})\end{array}$ & $\begin{array}{c}\text { Colour difference } \\
\Delta \mathrm{E}_{2000} \text { for 2 orders }- \\
\text { short interval }-(6 \mathrm{hrs})\end{array}$ & $\begin{array}{c}\text { Colour difference } \\
\mathrm{E}_{2000} \text { for 2 orders }- \\
\text { short interval }-(6 \mathrm{hrs})\end{array}$ & $\begin{array}{c}\text { Colour difference } \\
\Delta \mathrm{E}_{2000} \text { for } 2 \text { orders }- \\
\text { short interval }-(6 \mathrm{hrs})\end{array}$ \\
\hline & EPP1 & EPP2 & EPP1 & EPP2 \\
\hline Cyan & Matt coated board & Matt coated board & Offset uncoated board & Offset uncoated board \\
\hline Magenta & 0.60 & 0,91 & 0.53 & 0,93 \\
\hline Yellow & 0.65 & 1,14 & 0.30 & 1,19 \\
\hline
\end{tabular}

The results of table 1 show that both types of board in Printing Press 1 (EPP 1) exhibit a negligible $\Delta \mathrm{E}_{2000}$ over short periods of time 0.27-0.65. With a re-print after a long period of time in table 2, Printing Press 1 (EPP 1) yields a $\Delta E_{2000}$ value between 1.89 and 2.90, which is within tolerance values as set for sheet offset printing, for example. The values correspond completely to the digital prints validation standard ISO 12647 2/7/8 (International Organization for Standardization, ISO 12647-2:2013, 2013; International Organization 
for Standardization, ISO 12647-7:2016, 2016; International Organization for Standardization, ISO/DIS 12647-8, 2012). Electrophotographic print presses allow for the required accuracy of re-printing of circulations. In table 2 one can observe the comparison drawn between Printing Presses 1 and 2 (EPP 1 and EPP 2) over a longer period of time (four months) between two orders. In the case of re-print after a long period of time Printing Press 2 (EPP 2) yields difference values $\Delta \mathrm{E}_{2000}$ between 3.12 and 4.88 , which again is within the tolerable values for matt board and over the limit for offset board. It is due noting, that while testing colour change over long period of time, team members used different batches of paper, different Printing Press calibrations, etc., which in turn inevitably affects colours.

Table 2: Colour variationss $\triangle E_{2000}$ for $C M Y$ between two orders over long period of time for matt coated and offset uncoated boards, printed on EPP1 and EPP2

\begin{tabular}{|c|c|c|c|c|}
\hline & $\begin{array}{l}\text { Colour difference } \\
\Delta \mathrm{E}_{2000} \text { for } 2 \text { orders - } \\
\text { long interval- (4 } \\
\text { months) }\end{array}$ & $\begin{array}{l}\text { Colour difference } \\
\Delta \mathrm{E}_{2000} \text { for } 2 \text { orders - } \\
\text { long interval- }(4 \\
\text { months) }\end{array}$ & $\begin{array}{l}\text { Colour difference } \Delta \mathrm{E}_{76} \\
\text { for } 2 \text { orders - long } \\
\text { interval- (4 months) }\end{array}$ & $\begin{array}{l}\text { Colour difference } \Delta \mathrm{E}_{76} \\
\text { for } 2 \text { orders - long } \\
\text { interval- (4 months) }\end{array}$ \\
\hline & EPP1 & EPP2 & EPP1 & EPP2 \\
\hline & Matt coated board & Matt coated board & Offset uncoated board & Offset uncoated board \\
\hline Cyan & 1.89 & 3.12 & 2.58 & 4.36 \\
\hline Magenta & 1.94 & 3.25 & 2.66 & 4.51 \\
\hline Yellow & 2.03 & 3.46 & 2.90 & 4.88 \\
\hline
\end{tabular}

\section{CONCLUSIONS}

Based on the results obtained within the scope of this paper, the following conclusions could be presented:

1. This paper offered a method to investigate colour tone variations with the aid of parallel measurement of optical density variation $\Delta \mathrm{D}$ and colour differences $\Delta \mathrm{E}_{76}$ and $\Delta \mathrm{E}_{2000}$ within the circulation. Each of these factors brings valuable information regarding colour tone variations.

2. Results show a very good overall distribution and small delineations from the average of $\Delta \mathrm{D}$ for the print run on EPP1. As a function of colours vary between $\Delta \mathrm{D}$ from 0.01 to 0.05 . Results also show good distribution and larger deviances from the average of $\triangle \mathrm{D}$ on the print run of EPP2. As a function of colours vary between $\Delta \mathrm{D}$ from 0.04 to 0.15

3. The experimental results regarding colour characteristics variation in the circulation, in terms of $\Delta \mathrm{E}_{76}$ and $\Delta \mathrm{E}_{2000}$ show minimal variation on $\mathrm{EPP} 1$ ( $\Delta \mathrm{E}_{2000}$ from 0.02 to 1.99), and somewhat worse variations with large delta values for EPP2 ( $\Delta \mathrm{E}_{2000}$ from 0.10 to 2.93). Both Printing Presses can maintain stability and consistency of colours within a circulation, which in turn is of paramount importance for their practical use.

4. After analysing the results over a brief period, we have established that EPP1 and EPP2 both show good readings in terms of repeatability. EPP1 has $\Delta \mathrm{E}_{2000}$ variations of $\Delta \mathrm{E}_{2000}$ from 0.3 to 0.6 , and EPP2 $\Delta \mathrm{E}_{2000}$ from 0.9 to 1.2 .

5. Investigation also demonstrated that over long periods (4 months) both EPP1 and EPP2 exhibit different repeatability rates. EPP1 has far superior readings compared to its counterpart. The repeatability variations with that Printing Press over 4 months (for both media used) is within the $\Delta \mathrm{E}_{2000}$ from 1.89 to 2.9. As a point of reference, EPP2 yielded out variance values in the range $\Delta \mathrm{E}_{2000}$ from 3,1 to 4,88 . The presence of such high values with EPP2 would, inevitably, lead to problems in case of reprint.

6. From all results obtained during this experiment in real industrial conditions, one can conclude that the two Electrophotographic Printing Presses from the mid-price tier give excellent colour variations results over brief periods. Over longer periods of time, the two systems begin to diverge significantly. EPP1 holds good repeatability rate, whereas EPP2 shows large colour variations. This is most likely due to the different calibration methods from the manufacturers, as well as to the varied sensitivity of the two Printing Presses regarding the materials used, and las but not least the impact of environment conditions changes. Results show that the print hall observes clear, well-defined rules throughout the production process - from the provision and storage of the printing media to the very printing. These rules may include the implementation of an ISO standard, combined with internal rules of the print house. Here is why it is important and necessary, for the users of digital and conventional presses, to use and adhere, as much as possible, to a defined set of rules, regardless if it is an ISO standard or an alternative instrument. 


\section{REFERENCES}

[1] ICC, International Color Consortium, URL: www.color.org (last request: 2020-09-20.)

[2] International Organization for Standardization, ISO/DIS 12647-8, Graphic technology - Process control for the production of half-tone colour separations, proof and production prints - Part 8: Validation print processes working directly from digital data, 2012.

[3] International Organization for Standardization, ISO 12647-2:2013 Graphic technology - Process control for the production of half-tone colour separations, proof and production prints - Part 2: Offset lithographic processes, International Organization for Standardization, 2013.

[4] International Organization for Standardization, ISO 12647-7:2016 Graphic technology - Process control for the production of halftone colour separations, proof and production prints - Part 7: Proofing processes working directly from digital data, 2016.

[5] Kachin, N., Spiridonov, I.: "Printing Processes - Part 1, Theoretical bases", (Pleyada, Sofia,2000).

[6] Kachin, N., Spiridonov, I.: "Optical Density and Colour Difference in Printing on Different Types of Paper", Cellulose Chemistry And Technology 39(3-4), 255-264, 2004.

[7] Kipphan, H.: "Handbook of Print Media", (Springer-Verlag Berlin Heidelberg, Heidelberg, 2001), doi: 10.1007/978-3-540-29900-4.

[8] Kraushaar, A.: "Process Standard Digital", Handbook 2018, URL: www.fogra.org (last request: 2020-09-15.).

[9] MediaStandard Print 2018, Technical Guidelines for Data, Proof and Production Run Printing, URL: www.bvdm-online.de/handreichungen (last request: 2020-09-03.).

(c) $\underset{\mathrm{ar}}{\mathrm{ar}}$

(C) 2020 Authors. Published by the University of Novi Sad, Faculty of Technical Sciences, Department of Graphic Engineering and Design. This article is an open access article distributed under the terms and conditions of the Creative Commons Attribution license 3.0 Serbia (http://creativecommons.org/licenses/by/3.0/rs/). 